\title{
面心立方 $\mathrm{Ni}-\mathrm{Fe}$ 合金単結晶における 誘起単軸磁気異方性の結晶方位依存性*
}

青 柳 恵 三**

Keizô Aoyagi: Crystal Orientation Dependence of Induced Uniaxial Magnetic Anisotropy in Face-Centered Cubic Nickel-Iron Single Crystals. The induced uniaxial ferromagnetic anisotfopy energy, $E_{\varepsilon}$, as a function of the crystal orientation has been measured, using a torque magnetometer, with magnetically annealed (110) disc singie crystals of 17 and $46 \% \mathrm{Fe}-\mathrm{Ni}$ alloys. It has been found that $E_{u}$ may be well expressed by a formula

$$
E_{u}=-K\left(\sum_{i} \alpha_{i}^{2} \beta_{i}^{2}+k \sum_{j>i} \alpha_{i} \alpha_{j} \beta_{i} \beta_{j}\right)
$$

where $K$ is a positive constant, $k$ a numerical factor, and $\alpha_{i}{ }^{\prime} \mathrm{s}$ and $\beta_{i}{ }^{\prime} \mathrm{s}(i=1,2,3)$ are the direction cosines of magnetization vectors during the torque measurement and during magnetic annealing, respectively, and that the factor $k$ is $2 \sim 3$, except for $\mathrm{Ni}-\mathrm{Fe}$ alloys nearby $\mathrm{Ni}_{3} \mathrm{Fe}$, being smaller than 4 as expected from the directional order theory for face-centered cubic lattice. This difference may partly be due to the fact that the contribution from the secondneighbor atoms is neglected in the theory, and rather large values of $k$ for $\mathrm{Ni}$-Fe alloys nearby $\mathrm{Ni}_{3} \mathrm{Fe}$ may be due to the presence of superlattice.

(Received March 9, 1961)

\section{I. 緒 論}

第 3 部(1)に乱いて著者は 12 和よび $20 \% \mathrm{Co}-\mathrm{Ni}$ 合金の 単結晶試料にいて䛪起磁気異万性の土ネルギー $E_{u}$ の結

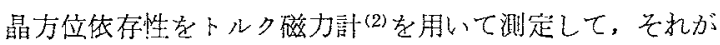
一般式

$$
E_{u}=-K\left(\sum_{i} \alpha_{i}^{2} \beta_{i}^{2}+k \sum_{>2} \alpha_{i} \alpha_{i} \beta_{i} \beta_{i}\right),
$$

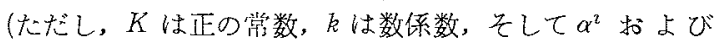
$\beta_{i}(i=1,2,3)$ はそれぞれトルク测定中和よび磁致钝中の 磁化ベクトルの方向余弦によつてをく表現されそとして 係数 $k$ の値は合金の組成に拘放らず2〜3であることを見 出だした。

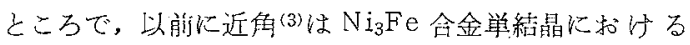

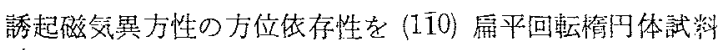

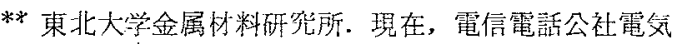
通信研究所

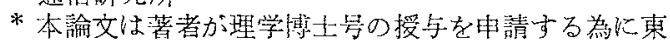
北大学に提出した学位諭文の一部である。

(1) 青楖: 本誌, 25 (1961), 424 .

(2) 山本, 谷口, 猆柳: 本誌, 25 (1961)，415(第 1 部).

(3) 近角: J.Phys. Soc. Japan, $11(1956), 551$.
を用小て則忌した，彼によつて得られた結果と $20 \% \mathrm{Co}$ $\mathrm{Ni}$ 合金についてわれわれが得たそれとの此較を Fig.1に 示した。これから判るように，近角は $\mathrm{Ni}_{3} \mathrm{Fe}$ 合金に対し て $k=8.5$ なる値を見出だしたが，これは著者が第而部(1) に批いて 12 执よび $20 \% \mathrm{Co}-\mathrm{Ni}$ 対して得た $k=2 \sim 3 な る$ 値よりる非管に大きい。そこで，本第 4 部に执いてこの

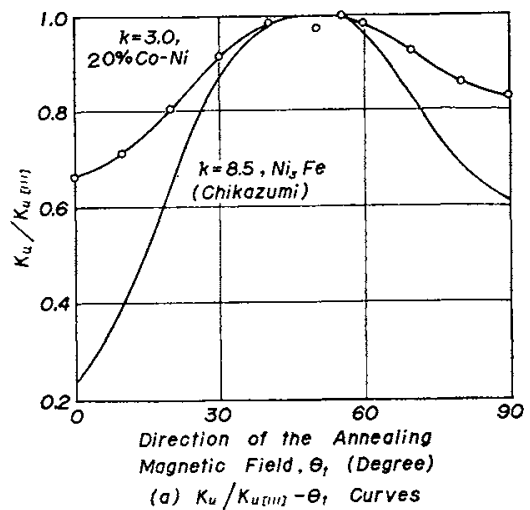

よ5なに优の相違が合金系の相違は原因するか或いは Ni$\mathrm{Fe}$ 系には $\mathrm{Ni}_{3} \mathrm{Fe}$ 規則格子が存在するとに対し，Ni-Co 系 
に颃いては規則格子が存任しない、しとに原因するかを明 らかにするために， $\mathrm{Ni}_{3} \mathrm{Fe} に$ 近い17\% Fe-Ni 合金就よび

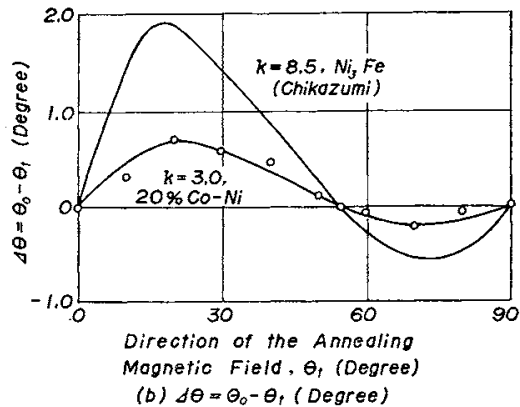

Fig. 1 Comparison of the crystal orientation dependence of (a) the uniaxial ferromagnetic anisotropy, $K_{u}$, and of (b) the deviation of the direction of easy magnetization from that of the annealing magnetic field, $\Delta \theta$, in $\mathrm{Ni}_{3} \mathrm{Fe}$ alloy measured by Chikazumi (3) and in $12 \% \mathrm{Co}-\mathrm{Ni}$ alloy measured by us.

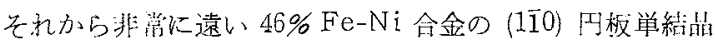
を用いて $K_{u}$ の方位依存性を研究した。

\section{II. 单 結 晶 試 料}

磁気異方性泡定のために用いたトルク磁力棓性第1 部 ${ }^{(2)}$

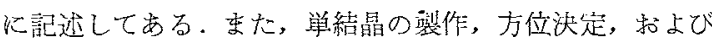
円板の成形のための手繳さも第 2 部(5)に記述した通りであ る。广和，単結昆を裂作するための原料は笔解二ッケルと 電解鉄である，試料の組成の決定は第 3 激(1)以和ける $\mathrm{Ni}$ Co 合金単結晶の場合之同じ二つの方法(6)の外见単結晶の，

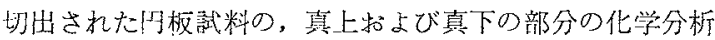
によつても行われた。これらの汰定の結果は Table 1 に 示されているが，以下に捈いてはX線螢光分析によりて

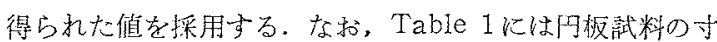
法む与えてある。語料は前以て真导中で $1000^{\circ} \mathrm{C} て ゙ 1$ 時間 焼晸された。

\section{III. 实験結果}

测定に際して行つた試料の蓺爬理は第 3 部(1)に㟔ける

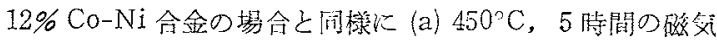

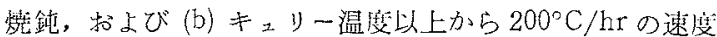

での磁場中冷却である。测定されたトルク峴線も12\% Co$\mathrm{Ni}$ 単結晶の場合(1)と同㥞にしてフーリェ解析された。

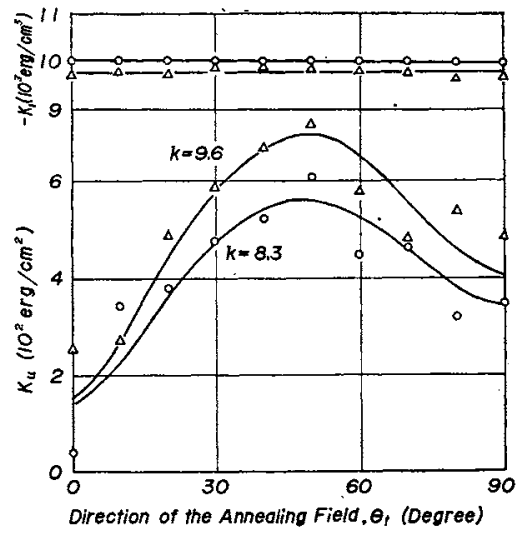

(a) $K_{u}$ and $K_{1}$ vs. $\theta_{t}$

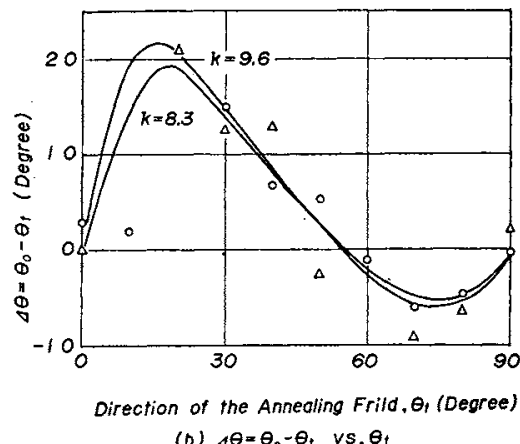

(D) $\Delta \theta=\theta_{0}-\theta_{t}$ vs. $\theta_{t}$

Fig.2 Uniaxial and first cubic ferromagnetic anisotropy constants, $K_{u}$ and $K_{1}$, and the deviation of easy magnetization of the uniaxial anisotropy, $\theta_{o}$, from the direction of the annealing magnetic field, $\theta_{t}$, as dependent on $\theta_{t}$ in a (110) disc of $17 \% \mathrm{Fe}-\mathrm{Ni}$ alloy as annealed at $450^{\circ} \mathrm{C}$ for 5 hours and cooled rapidly in magnetic field of 1700 Oe applied parallel to the plate surface $(O)$ and as cooled from above the Curie temperature at the rate of $200^{\circ} \mathrm{C} / \mathrm{hr}$ in the same magnetic field $(\Delta)$. Solid curves in (a) and (b) are calculated using $k=8.3$ and $k=9.6$, respectively.

$17 \% \mathrm{Fe}-\mathrm{Ni}$ 合金に対する $K_{u}$ 岕よび $\Delta \theta$ と $\theta_{t}$ との関係

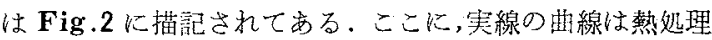

Table 1 Compositions and dimensions of (110) disc single crystal specimens of nickel-iron alloys.

\begin{tabular}{|c|c|c|c|c|c|}
\hline \multirow{2}{*}{$\begin{array}{l}\text { Specimen } \\
\text { mark }\end{array}$} & \multicolumn{3}{|c|}{ Composition (wt. - \% Co) determined } & \multicolumn{2}{|c|}{ Dimensions } \\
\hline & $\begin{array}{l}\text { by X-ray fluorescence } \\
\text { method }\end{array}$ & by chemical analysis & from $K_{1}$ data & $\begin{array}{c}\text { Diameter } \\
(\mathrm{mm})\end{array}$ & $\begin{array}{l}\text { Thickness } \\
(\mathrm{mm})\end{array}$ \\
\hline $\begin{array}{l}\mathrm{Ni}-\mathrm{Fe}, 1 \\
\mathrm{Ni}-\mathrm{Fe}, 2\end{array}$ & $\begin{array}{l}17 \% \mathrm{Fe} \\
46 \% \mathrm{Fe}\end{array}$ & $\begin{array}{l}18.09 \% \mathrm{Fe} \\
48.36 \% \mathrm{Fe}\end{array}$ & $\begin{array}{l}16 \% \mathrm{Fe} \\
43 \% \mathrm{Fe}\end{array}$ & $\begin{array}{l}12.232 \\
10.475\end{array}$ & $\begin{array}{l}0.470 \\
0.483\end{array}$ \\
\hline
\end{tabular}

(4) $\mathrm{Ni}-\mathrm{Co}$ 系に却ける規則格子 $\mathrm{Ni}_{3} \mathrm{Co}$ の存在に対して

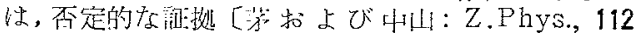

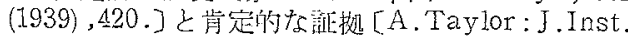
Metals, $77(1950), 585 ;$ V.Z.Yao : J.Chem. Phys., $33(1960), 741]$ とがありて狄定的ではない.

(5) 山本, 行口, 装柳: 本誌, 25 (1961)，419(第 2 部).

(6) 第I等軸磁氛異方性活数 $K_{1}$ ○侹の比較による組成 の決定记は R.M.Bozorth: Rev.Mod. Phys., 25 (1953)，42のdataを用いた。 (a)に対してはk=8.3を用い，东た熱処理(b)に対しては

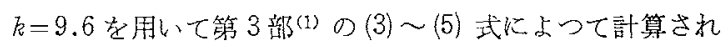
たものである.これらのれの位は近角(3)火よつて $\mathrm{Ni}_{3} \mathrm{Fe}$ 合金について得られた 8.5 な値とよく一致するが，し かし 12 和よび $20 \% \mathrm{CO}-\mathrm{Ni}$ 合金比対する2〜3なる健(1)よ

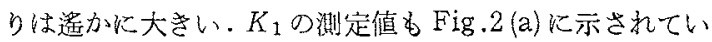


る、 $K_{1}$ は $\theta_{t}$ 亿は依存しないが，しかしすでに知られてい

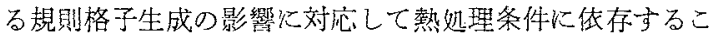
とが知られる。

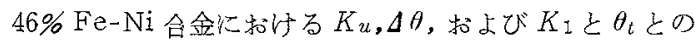
䦦係はFig.3に示されている。ここに笑線の曲線は熱処

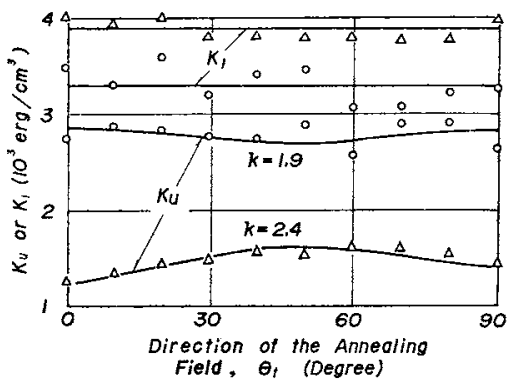

(a) $K_{u}$ and $K_{t}$ vs $\theta$

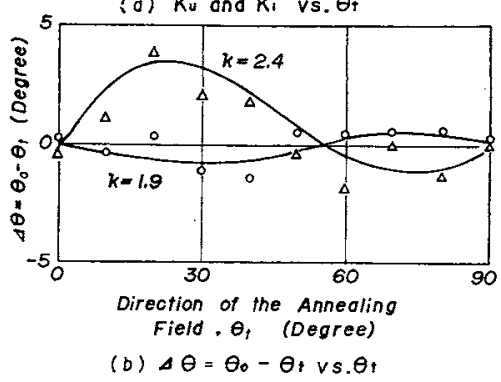

Fig. 3 Uniaxial and first cubic ferromagnetic anisotropy constants, $K_{u}$ and $K_{1}$, and the deviation of easy magnetization of the uniaxial anisotropy, $\theta_{o}$, from the direction of the annealing magnetic field, $\theta_{t}$, as dependent on $\theta_{t}$ in a (110) disc of $46 \% \mathrm{Fe}-\mathrm{Ni}$ alloy as annealed at $450^{\circ} \mathrm{C}$ for 5 hours and cooled rapidly in magnetic field of 1700 Oe applied parallel to the plate surface (O) and as cooled from above the Curie temperature at the rate of $200^{\circ} \mathrm{C} / \mathrm{hr}$ in the same magnetic field $(\Delta)$. Solid curves in (a) and (b) are calculated, using $k=1.9$ and $k=2.4$, respectively.

理(a)和よび(b)に対してはそれ无れれ=1.9および2.4な る值を用いて部算されたるのである。これらの

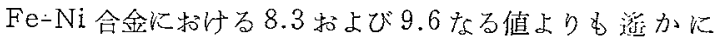

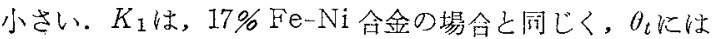
依存しないが，熱起理条件比依存する。な招，KIの符号 は46\% Fe-Ni 合金に詨しては正で, そして $17 \% \mathrm{Fe}-\mathrm{Ni}$ 合 金に対して負である。

\section{IV、第 3 部および第 4 部における 実験結果の論議}

われわれが第 3 部(1)和よび本第4 部に执いて2 種の Ni一

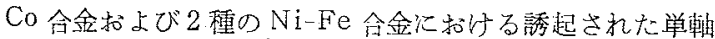

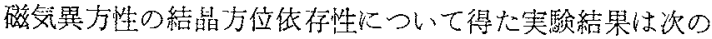

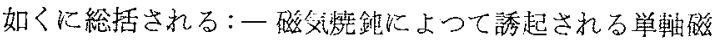
気異方性は第 3 部(1)の(1)'式以よつて践示される。その 式の中の係数 kの值はTable 2 に与克られ，また㞦と 合金組成との関係はFig.4に描記されている。これらの袁
执よび図によれば，にの攧は耐会金系に共通に一般的には 2〜3であるが，ただ $\mathrm{Ni}_{3} \mathrm{Fe}$ 近傍の $\mathrm{Ni}-\mathrm{Fe}$ 合金に対しての

Table 2 Measured data on the $k$ factor characterizing the orientational dependence of the induced uniaxial ferromagnetic anisotropy and on the first cubic anisotropy constant, $K_{1}$, in nicke1-iron alloys. Chikazumi's(3) measured data on $\mathrm{Ni}_{3} \mathrm{Fe}$ alloy are also given for comparison.

\begin{tabular}{c|c|c|c}
\hline \multirow{2}{*}{ Alloy } & $\begin{array}{c}\text { Heattreatment in } \\
\text { magnetic field }\end{array}$ & $k$ & $K_{1}\left(103 \mathrm{erg} / \mathrm{cm}^{3}\right)$ \\
\hline $17 \% \mathrm{Fe}-\mathrm{Ni}\{$ & $200^{\circ} \mathrm{C} / \mathrm{hr}$ & 9.6 & -9.8 \\
$46 \% \mathrm{Fe}-\mathrm{Ni}\{$ & $450^{\circ} \mathrm{C}, 5 \mathrm{hrs}$ & 8.3 & -10.0 \\
& $200^{\circ} \mathrm{C} / \mathrm{hr}$ & 2.4 & 3.9 \\
$\mathrm{Ni}$ & $450^{\circ} \mathrm{C}, 5 \mathrm{hrs}$ & 1.9 & 3.3 \\
& $840^{\circ} \mathrm{C} / \mathrm{hr}$ & 8.5 & -1.7 \\
\hline
\end{tabular}

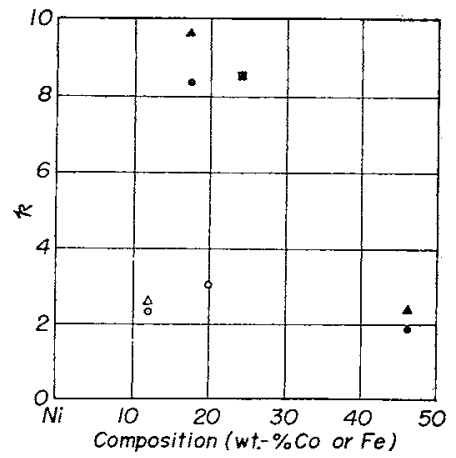

Fig.4 Composition dependence of the $k$ factor in nickel-cobalt $(O, \Delta)$ and nickeliron ( $\mathbf{1})$ alloys as annealed in magnetic field at $450^{\circ} \mathrm{C}$ for 5 hours and cooled rapidly $(O,-)$ and as cooled in magnetic field from above the Curie temperature at the rate of $200^{\circ} \mathrm{C} / \mathrm{hr}(\Delta, \mathbf{\Delta})$, Chikazumi's (3) measured data with $\mathrm{Ni}_{3} \mathrm{Fe}$ is also plotted for comparison (

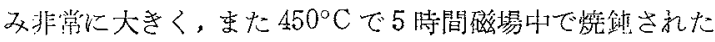
状熊のkの值性磁㘯中でキュリー温度上から約 $200^{\circ} \mathrm{C} / \mathrm{hr}$ の速度で㐨却された状態のそれよりも籍比少し小さい，從 つて，埇心立方固溶体合金心拈け名 $k$ の犆は規則格子が形 成される組成籁祭を除けば，組成及び合金系の如何以拘わ らず2〜3であるといい得る。

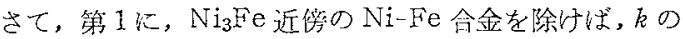
值は谷口ー山本(7)和よびNéel(8) によつて提出された directional order 理諭加面心立方国浴体に対して期待され るムなる健よりる小さいことに注目される。このことの原 因の一部位强胜原子聞の異方的な相互作用が理諭心扣い て仮定されている程には短範国的ではないことであるう。

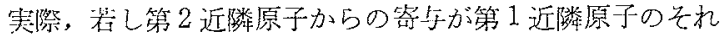
に単純儿重最すると考光得られるならば，にの值は 4 より

(7) 谷口, H本: Sci. Rep. RITU,A6 (1954), 330; 谷 口: Sci. Rep. RITU, A7 (1955), 269.

(8) L.Née]: Compt. rend., $237(1953), 1613 ; \mathrm{J}$. de phys. rad., $15(1954), 225$. 
も小さいことは容易に示される、亦なおち，面心立方格子 に括方第 2 近隣原子は単純立方格子を形成するから，そ れらによる誘起単軸磁気異方性エネルギー $E_{\text {(2) }}^{(2)}$

$$
E_{u}^{(2)}=-K^{\langle 2\rangle} \alpha_{i}^{2} \beta_{i}^{2}
$$

なる形をもつ ${ }^{(8)(9)}$. 従つて全体の誘起阙父暴方栍 $E_{u}$ は

$$
\begin{aligned}
E_{u}= & E_{u}^{(1)}+E_{u}^{(2)}=-\left(K^{(1)}+K^{(2)}\right) \\
& \times\left\{\sum_{i} \alpha_{i}^{2} \beta_{i}^{2}+k^{\prime} \sum_{i>i} \alpha_{i} \alpha_{j} \beta_{i} \beta_{j}\right\},
\end{aligned}
$$

たたし

$$
k^{\prime}=4 /\left\{1+\left(K^{(2)} / K^{(1)}\right)\right\}
$$

しからば， $K^{(2)} / K^{(1)}>0$ であるから，长く4になる。

第 2 に, $\mathrm{Ni}_{3} \mathrm{Fe}$ 近傍の $\mathrm{Fe}-\mathrm{Ni}$ 合金に和いて規则格子生 成のためにkの值が大きくなつていることに注目される。

さらに，Fig.4をよく見ると，Ni-Co 合金に和いては $k$ が Co 证の增加と共に少しく增加することが知られる。斯㥞 なkの組成低存性は実際の固溶体の非理想性によつて訪明 されるように思われる.Néelの非理想固溶体の場合に対す る玨諭的取报いは directional order t含む原子配置の混 合エントロピーを考虑に入れていないから, directional order と固溶体の非理想性との相関を硑密には計算し得な

(9) 谷口: Sci. Rep. RITU, A8(1956), 173.
い、極く最近我々の斫究室の岩田(9)はこの闍題を面心立方 格子については 4 面体近似を用いて取扱い，そしてNéel によつて得られた誘起磁気異方性の組成依存性は修正され て規則化エネルギー $v$ 従つて臨界温度は雨合金系に対して 約 2 なる俰数の壁度改善され，そして溶質濃度の增大と共 に，Ni-Co 合金に拈引る加く $v<0$ なる場合には $k$ は增大 し，そして Fe-Ni 合金に拈りる如くv>0なる場合には $k$ は娍少することを示した。この岩田によつて得られた 組成低存性は Fig.4k示された Ni-Co 合金におけるとれ と定性的に一致する.

斯様にして, 谷口ー山本 ${ }^{(7)}$ およよ゙ Néel(8)によつて提出さ れた directional order 理諭は，実験結果の細かい，点の説 明に対しては若干困難があるけれどす,他の何れの理論(11) よりも実験結果をよく説明することが出来るといい得る.

閣筆寸るに当り，著者は本研究に対して与えられた山本 美点蜼教授於よび谷口哲助教授の懇切な指導と激励亚びに 岩田孝夫助教授の有益な忠告とに対して心加感謝する次 第である.

(10) 岩目: Trans. JIMに近く発表.

(11) 例えばC.D.Graham: Magnetic Annealing, Magnetic Properties of Metals and Alloys, ASM (1959); E.W.Lee: Adv. Phys., 8(1959), No.31 参照. 